\title{
Fístula ciego-íleo-cutánea. Una complicación rara de tuberculosis urinaria
}

\section{Ceacum-ilio-cutaneous fistula. A rare complication of urinary tuberculosis}

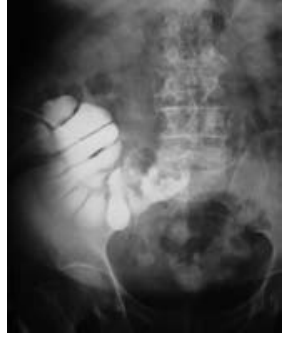

Figura 1 - Estudio con contraste de la ileostomía que documenta una comunicación con el ciego con paso del contraste para colon ascendente.

J. Cabral Ribeiro ${ }^{a, *}$, C. Rolanda ${ }^{b}$ y A. Santos ${ }^{a}$

a Servicio de Urología, Hospital de São Marcos, Braga, Portugal 'Servicio de Gastroenterologia, Hospital de São Marcos, Braga, Portugal

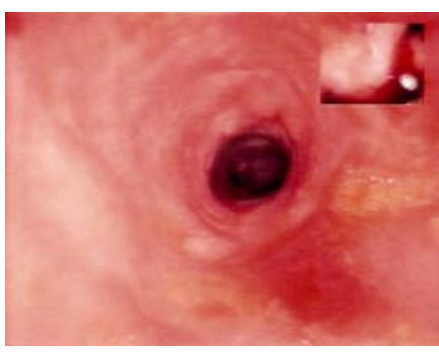

Figura 2 - Endoscopia por la ileostomía. Un bricker inflamatorio con un orificio de comunicación con el colon.

*Autor para correspondencia.

Correos electrónicos: jcabralribeiro@netcabo.pt, jcabral@hsmbra ga.min-saude.pt (J. Cabral Ribeiro).

doi: 10.1016/j.acuro.2010.03.017

\section{Enfisema subcutáneo abdominal tras traumatismo escrotal}

\section{Abdominal subcutaneous emphysema following scrotal trauma}

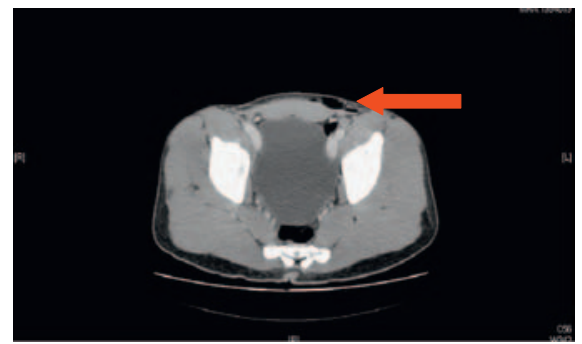

Figura 1 - TC abdominopélvico: enfisema subcutáneo en escroto izquierdo anterior a sínfisis pubiana.

D. Gallego Vilar ${ }^{a}$,* I. Povo Martin ${ }^{a}$, J. Miralles Aguado ${ }^{a}$,

P. Romero Crespo ${ }^{b}$, V. Gimeno Argente ${ }^{a}$, M. Ferrer Royo ${ }^{b}$,

M. Bosquet Sanz ${ }^{a}$ y J. Gallego Gómez ${ }^{a}$

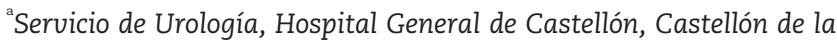
Plana, España

'Servicio de Urgencias, Hospital General de Castellón, Castellón de la Plana, España

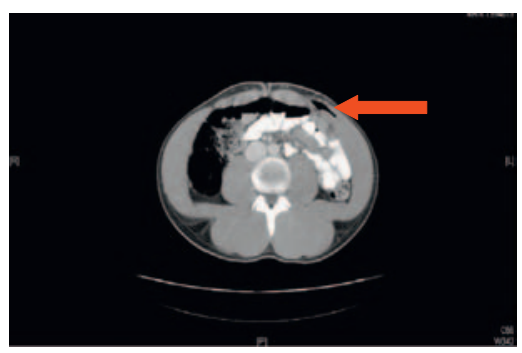

Figura 2 - TC abdominopélvico: enfisema subcutáneo desde escroto izquierdo hasta pared abdominal superior, entre musculatura del recto anterior izquierdo y oblicuos izquierdos. Ausencia de líquido libre intraperitoneal.

*Autor para correspondencia.

Correo electrónico:

dagalvi@hotmail.com (D. Gallego Vilar).

doi: 10.1016/j.acuro.2010.03.018 